\title{
Sexualidade e imprensa
}

Patrícia Espirito Santo*

\section{RESUMO}

Este artigo tem como objetivo discutir sobre a representação social da sexualidade humana construída a partir das notícias veiculadas pela imprensa no Brasil.

\section{INTRODUÇÃO}

Quem tem a palavra constrói identidades pessoais e sociais. Hoje a realidade parece ser só aquilo que aparece na mídia - o que está lá, existe; o que não está, não existe. Isto faz com que nos perguntemos, freqüentemente, se o mundo real é o que lemos, vemos e ouvimos na mídia ou é aquele em que vivemos todos os dias.

Não quer dizer que o quadro de desgraças mostrado todos os dias na mídia seja inventado. Ele é apenas incompleto. Ao optar em destacar em

* Bacharel em Comunicação Social com especializações em Jornalismo pela PUC/MG, pós-graduada em educação sexual pela SBRASH. 
sua primeira página uma foto de adolescentes grávidas ou de mulheres que foram espancadas pelos maridos, o jornal ou revista não está lançando mão de artifícios de uma fotomontagem. O que está sendo mostrado realmente existe. "Mas, ao optar sistematicamente pela publicação de cenas como essas - e ignorar uma infinidade de outras, igualmente reais mas positivas ou neutras -, a imprensa transmite a impressão de que só existe esse tipo de realidade patológica no Brasil. A conseqüência é que fatos verdadeiros acabam conduzindo freqüentemente a conclusões falsas"'.

Já foram feitos estudos interessantes sobre o que determinados povos pensam de outros povos. Essa opinião está baseada, principalmente, nas informações que as pessoas recebem. Uma pesquisa feita há alguns anos mostrou que a cada 100 notícias enviadas da Associação de Imprensa de Buenos Aires para o quartel central dos Estados Unidos, apenas 8 eram aproveitadas. Mas o mais sério era que das 8 aproveitadas, 4 eram notícias que falavam de violência e de criminalidade - quando das 100 originais, 10 eram sobre $o$ assunto (notícias sobre violência e criminalidade representam apenas $10 \%$ das notícias redigidas e $50 \%$ das publicadas).

Outros estudos revelam surpresas no que se refere à importância da comunicação no campo das eleições. Verificou-se que a maioria absoluta dos candidatos que trabalham em algum meio de comunicação, principalmente televisão e rádio, se elege. Enquanto apenas de 5 a $10 \%$ dos candidatos não comunicadores se elegem, entre 80 a $90 \%$ dos candidatos comunicadores conseguem uma vaga. Aí fica a pergunta: Qual o peso social na formação da consciência coletiva (e no reforço de preconceitos) que existe entre um famoso apresentador de TV e o peso social na formação da consciência coletiva do mais renomado pesquisador?

\section{Para Ana Maria Braga, Aids é coisa de idiota}

\section{[...] Na última Segunda, no "Note Anote", [...], a apresen-} tadora Ana Maria Braga disputava com o boneco Loro José um concurso de piadas. [...] Ana Maria apelou: "Qual o significado da palavra Aids?" [...] A loira da Record soltou bem pausadamente: "Agora Idiota Durma Sozinho". E todos riram. E ela repetiu.

Folha de São Paulo - p. 04

21.03.99 - TV Folha

Podemos dizer que atualmente é a comunicação que constrói a realidade, que quem detém a construção desta realidade detém também o poder sobre a existência das coisas, sobre a criação da opinião pública. "A pergun- 
ta é se existe opinião pública ou opinião publicada? Como se forma a opinião pública num país onde milhões de pessoas só sabem um determinado nível de fatos (notícias) que são selecionadas e editadas pelas grandes redes de televisão? Quando a mídia destaca em sua pauta os problemas da violência, o Ibope recolhe na outra ponta a violência como a primeira preocupação dos moradores dos grandes centros urbanos. A onda depois, sem que a violência diminua, passa para a hiperinflação, a corrupção ou a cólera, e a preocupação dominante varia segundo as emissoras"2.

Seria reducionista e simplista afirmar que a consciência coletiva responde automaticamente ao que se vê na TV e lê nos jornais e revistas. Porém, não podemos negar que a consciência coletiva no Brasil se informa sobre alguns temas nacionais e internacionais - sobre um determinado recorte do que seja a realidade - basicamente a partir do que vê na TV, lê nos jornais e revistas. Quando vista na TV, a realidade ganha uma dimensão maior ainda pois a imagem torna a realidade "mais real", adquire importância porque visível.

A televisão estabelece uma conexão aparentemente lógica entre mostrar e demonstrar, isto é, se mostra, está comprovando o que diz. Mostrar é igual a demonstrar, a provar, a comparar. "A força da imagem é tão evidente que torna-se difícil não fazer essa associação comprovatória. Se uma imagem me impressiona, é verdadeira, pensamos consciente ou inconcientemente".

A imprensa constrói realidades também através da generalização a partir de uma situação concreta. Do individual, ela tira conclusões sobre o geral. Muito comumente, uma situação isolada converte-se em situação padrão.

A camisinha Feminina

Pesquisa do Ministério da Saúde mostra as vantagens do uso de preservativo

A comerciária Heliete Ramos ficou aliviada. Não precisaria mais implorar ao namorado para que usasse a camisinha. Ela ganhou a sua no posto de saúde de Santíssimo e, ao experimentála, comprovou que, além de não atrapalhar o prazer sexual do rapaz, a camisinha feminina aumenta o orgasmo da mulher. [...]

Com o aro externo da camisinha friccionando o clitóris durante o ato sexual, a intensidade do orgasmo aumentou incrivelmente. Foi uma surpresa agradável da pesquisa (do Ministério da Saúde). Esta camisinha não tem a desvantagem da masculina, que, segundo os homens, atrapalha o prazer sexual [...].

O Globo - 05.09.99-p. 01

Jornal da Família 
Em outra reportagem publicada, em 01.11.98, na Folha de S. Paulo"Fome de pai deixa meninos perdidos" - o jornal apresenta como tendência algo que ele não tem elementos suficientes para caracterizar como tal. Falta de limites dos alunos nas escolas, aumento da delinqüência juvenil, adolescentes nos consultórios de terapeutas - tudo isso foi creditado ao fato de "a figura do pai está se tornando cada vez mais ausente."

A única base utilizada para afirmar isto foi uma pesquisa feita pela Datafolha que concluiu que o pai atualmente tem menos importância na família que a mãe. Segundo a pesquisa $-74 \%$ dos entrevistados consideram a mãe "muito importante", contra $66 \%$ que têm a mesma avaliação a respeito do pai. Esses dois percentuais não confirmam o alegado declínio da figura paterna porque não são confrontados com dados mais antigos.

Além do descompromisso com a apresentação que sustentem as generalizações, a imprensa de uma maneira geral, tem a tendência a aderir a análises que nada fazem além de entronizar o senso comum. Em 03 de maio de 98, a Folha de São Paulo constatou, por exemplo, que "Sexo, aborto e Aids explodem entre jovens". "Os números apresentados permitiam falar, na melhor das hipóteses, em aumento. Pior que o exagero do título, no entanto, foi a explicação para o fenômeno. Em resumo, concluiu-se que a culpa é da Carla Perez, pois "a imitação da TV leva as crianças ao sexo" 3 .

Outra tendência muito freqüente da imprensa é a de, ao colocar pedaços de imagens ou cenas juntas, em seqüência, criar-se novas relações, novos significados, que antes não existiam e que passam a ser considerados aceitáveis, "naturais", "normais". Colocando várias matérias em seqüência, num mesmo bloco e em dias sucessivos - como se fossem capítulos de uma novela, sobre o assassinato de uma atriz, o de várias criança e crimes semelhantes, acontecidos no Brasil e em outros países, multiplica-se a reação de indignação da população, o seu desejo de vingança. Isto favorece os defensores da pena de morte, o que não estava explícito em cada reportagem e nem talvez fosse a intenção dos produtores ${ }^{1}$.

\section{ESCREVENDO A HISTÓRIA}

Quem sempre retratou a história? Os historiadores. Porém, no seu trabalho, o historiador também não parte dos fatos, das fontes, no sentido mais extenso desse termo, com a ajuda dos quais constrói o que chamamos fatos históricos. Os constrói na medida em que seleciona materiais disponíveis em função de um certo critério de valor, como na medida em que os articula, conferindo-lhe a forma de acontecimentos históricos.

Os historiadores do presente são os jornalistas, que colhem fatos no seu acontecer. Que tipo de historiadores? "Para vários estudiosos da comunicação e da história, a ciência cedeu lugar ao jornalismo. A capacidade de penetração dos meios de comunicação de massa ofusca o trabalho científi- 
co. Na verdade, o poder do jornal é, de um modo geral, subestimado. Sua ingerência na vida do cidadão e da sociedade é tão habitual, "normal", que, como a linguagem, ele impregna o cotidiano, amalgama-se com a memória coletiva, envolve a consciência, dificultando o distanciamento crítico"4.

Quase sempre os meios de comunicação de massa (televisão, rádio, jornal e revista) são a única forma através da qual as pessoas têm conhecimento das mudanças que estão acontecendo no campo científico e de suas conseqüências na sua vida. Você, se lembra da primeira vez que ouviu falar na Aids? Bem provavelmente foi através de uma nota ou reportagem publicada pela grande imprensa internacional ou mesmo a brasileira.

Muitas vezes, as informações científicas estão nas notícias do dia-adia. A notícia sobre uma criança que não foi aceita em uma determinada escola por ser portadora do vírus HIV, traz, por exemplo, informações sobre as formas de contágio do vírus da Aids.

\section{PARCIALIDADE}

Cabe ao jornalista, ao redigir suas matérias, tentar ser tão isento quanto possível, não permitindo que o processamento da informação seja posto a serviço de fins políticos, ideológicos e pessoais. Entretanto, ao selecionar e dar pesos diferentes aos elementos das informações que serão veiculadas nos meios de comunicação decide-se como determinado aspecto da realidade será apresentado à opinião pública e isso é inevitável, já que uma isenção total por parte do jornalista é impossível.

Vamos partir de um pressuposto: nem mesmo a testemunha ocular traça um quadro ingênuo da cena. "Pois a experiência parece mostrar que ela própria traz à cena alguma coisa, que dela retira mais tarde e o mais das vezes, o que supõe ser o relato de um acontecimento é, na realidade, uma transfiguração dele. Os fatos que vemos dependem da posição em que estamos colocados e dos hábitos de nossos olhos"s.

O próprio leitor ou telespectador ao ler as notícias acaba por deixar que suas experiências e interpretações sobre sexualidade, normalidade e moralidade influenciem na compreensão da mesma. Porque o mesmo não pode acontecer com jornalistas e historiadores principalmente porque, como a maioria dos leitores, trazem eles inúmeros registros de preconceitos, mitos e tabus decorrentes de uma visão negativa do exercício da sexualidade presente na educação do homem há milênios?*

* Essa questão é tratada mais profundamente em SANTO, P. E. - Projeto de inclusão da disciplina Educação Sexual como matéria optativa nos cursos de Comunicação Social. Revista Brasileira de Sexualidade Humana, volume 10, n 1. São Paulo, 1999. 
Existem também aqueles jornalistas que, ao se dirigirem a alguém, não querem realmente obter uma informação. Querem apenas obter alguma forma de confirmação ou justificativa para aquilo que já decidiram escrever por já terem decidido, interiormente, que sua visão pessoal da sexualidade eqüivale à realidade. Declarações, fatos ou números que se contraponham a visão deles são ignorados; só é levado ao público o que combina com aquilo que o jornalista quer dizer (ou aceita).

Não existe objetividade no jornalismo. Ao escolher um assunto, redigir um texto e editá-lo o jornalista toma decisões de largas medidas subjetivas, influenciadas por suas posições pessoais, hábitos e emoções. Uma reportagem sobre a Casa de Partos, em Sapopemba, São Paulo, "Programa garante partos sem riscos", publicada na Folha de São Paulo de 29 de agosto de 1999 , informa que todos os partos ali realizados foram bemsucedidos - e normais.

"Por mais méritos que tenha a iniciativa, é falacioso exibir, como indicador de êxito, o fato de que nenhuma cesárea foi realizada no local desde sua inauguração, em outubro do ano passado. Nenhuma cesárea foi feita porque não há médicos na Casa de Partos, e sim enfermeiras com especialização em obstetrícia. O próprio jornal esclarece adiante que os casos mais complicados são encaminhados a um hospital"6.

"A reportagem é favorável mesmo", afirmou dias depois o autor do texto, Gilberto Dimenstein. "Ela força esperança. Como repórter, vi uma solução de saúde pública que dá certo" . A referência às cesáreas foi destacada na capa do jornal e na abertura da reportagem. Um dos principais textos desse material recebeu o seguinte título: "Programa de saúde garante partos sem riscos". Não garante, porque nada pode fazer isso. Na melhor das hipóteses, diminui os riscos ao mínimo. "É um defeito antigo da imprensa: não basta ser ruim, tem que ser o fim do mundo; não basta ser bom, tem que ser um conto de fadas. ${ }^{6,}$

Entretanto, isso não significa que o jornalista não tenha que buscar essa objetividade, ou seja, tentar ser o mais objetivo possível. Nessa busca pela objetividade possível, adotou-se a prática, para os assuntos que envolvam diferentes opiniões, ouvir os dois lados, que quase sempre apresentam comentários opostos. Dessa forma resolve-se o problema da imprensa, mas, certamente, permanecerá a dúvida do leitor.

Como atribuir à imprensa a responsabilidade pelas informações divergentes, se a mesma não tem competência científica para esclarecê-las? Se em tese essa parece ser a solução, na prática o jornal poderá estar passando a seus leitores pelo menos uma informação falsa, quando uma das versões apenas puder ser a verdadeira - em alguns casos as duas versões podem ser falsas. Devido seu imediatismo, as notícias que se apresentam como verdadeiras hoje, podem mostrar-se erradas amanhã. 
Como fica o leitor diante de informações contraditórias de dois cientistas sobre um tema em que não possui conhecimentos que permitam sua opção por uma ou outra versão?

Médicos divergem sobre ejaculação feminina

As mulheres ejaculam? O assunto, que continua controverso até os dias de hoje, ainda divide os especialistas em sexualidade humana e as próprias mulheres. [...]

O ginecologista Francisco Siervo Neto, de São Paulo, diz que nunca viu em seu consultório nenhuma mulher que contasse que teria a ejaculação.

O ginecologista Gerson Lopes, de Belo Horizonte, um dos maiores especialistas brasileiros em sexualidade da mulher, diz que já foi mais radical com relação à ejaculação feminina. [...]

No entanto, Lopes afirma que atendeu, recentemente, algumas pacientes que modificam um pouco suas idéias. Segundo ele, elas descreviam a ejaculação feminina com uma riqueza de detalhes que não deixava muita margem de dúvida com relação ao que acontecia em seu corpo. [...] "Talvez poucas mulheres, em alguns orgasmos especiais, consigam ter esse tipo de ejaculação".

Folha de S. Paulo - 18/06/99 - p. 03

Editoria Cotidiano

Na mesma página da Folha de S. Paulo, onde foi publicada a reportagem analisada acima, há outra controvérsia científica. "Ponto $G$ não é consenso entre médicos" - diz o título. A reportagem é aberta com a seguinte afirmativa: "Nem a ocorrência de dois tipos distintos de orgasmo (clitoriano e vaginal) e a existência real do "famoso" ponto G são consenso entre os médicos".

\section{CIENTISTAS X JORNALISTAS}

Não é tranqüilo o relacionamento entre jornalistas e cientistas. Os primeiros afirmam ter nos cientistas a principal, e algumas vezes única, fonte de informação sobre as pesquisas e descobertas científicas, e que por isso têm que acreditar em suas informações. Se estas estão erradas, a culpa não poderia, portanto, ser creditada a eles, jornalistas. Muitas vezes, os próprios cientistas levam suas dúvidas para os congressos, e o jornal, ao levar para a sociedade a discussão científica, acaba por transmitir em suas notícias da- 
dos incertos e, algumas vezes, errados. Mas informar sobre o que está sendo discutido, os pareceres dos médicos e as pesquisas em andamento não seria um dos papéis da imprensa?

\section{A informação perigosa}

A divulgação dos fatos ligados à área de saúde foi tema de uma teses levada à reunião da Sociedade Brasileira pelo Progresso da Ciência, realizada em Belém do Pará, em 1983, e representada na Conferência Nacional dos Jornalistas que se reuniu em Belo Horizonte no ano seguinte. $O$ autor desse trabalho, militante veterano da imprensa, mostrava as distorções, as lacunas e os erros cometidos nas notícias veiculadas sobre o assunto, em sua esmagadora maioria de responsabilidade das próprias fontes de informação e, em pequena parte, da afoiteza de alguns profissionais, principalmente dos mais novos, $e$ inexperientes, diante da aparente grandiosidade de um fato.

$$
\begin{gathered}
\text { Estado de Minas - } 29.06 .86 \text { - p. } 02 \\
\text { Editoria } 1^{\circ} \text { Caderno }
\end{gathered}
$$

Por sua vez os cientistas tentam controlar as notícias, recusando entrevistas ou condicionando-as a uma revisão do que foi escrito antes de sua publicação*; acusando jornalistas de criarem crises onde elas não existem, além de transformarem hipóteses científicas em esperança para a população. Os cientistas acusam os jornalistas de irresponsáveis ao noticiar sobre ciência, transformando muitas vezes hipóteses científicas em certezas para a população, enquanto jornalistas se queixam de ter nos cientistas sua única fonte de informação, o que os coloca nas mãos desses.

Freqüentemente as hipóteses ou pesquisas em andamento são apresentadas nos títulos como verdades e descobertas.

\section{Estresse altera a fertilidade}

Cigarro, maconha, álcool e estresse podem alterar a fertilidade masculina. $O$ estilo de vida é um dos fatores que podem

\footnotetext{
" O jornalista está constantemente "correndo contra o tempo". Esse é um dos fatores que impossibilita a revisão do texto por parte do entrevistado. Fora o fato de o entrevistado, muitas vezes, discordar do que está escrito, nem tanto por retratar uma inverdade, mas também por não coincidir com aquilo que ele julga interessante ser publicado de forma a promovê-lo perante a comunidade científica e a leiga.
} 
comprometer o número e a função dos espematozóides. [...] De acordo com Edson Borges Júnior, os fumantes têm dez vezes mais chance de sofrerem alteração no seu sêmen do que homens que não fumam.

Folha de S. Paulo - p. 03

Cotidiano - 09.08.98

Quando se lembra que grande parte dos leitores lê apenas os títulos das matérias percebe-se o sério risco de informar errado. Com relação aos títulos, nem sempre os mesmos destacam a informação de maior relevância do ponto de vista científico. Nem sempre o que é mais importante para a imprensa - um título que estimule o leitor a ler a matéria e/ou venda do jornal/revista - é o mais importante a ser divulgado, se considerarmos o jornal ou revista como instrumento de informação.

\section{Elas querem mais}

Mulheres de meia-idade passam a reivindicar seu direito sexo

[...] Uma pesquisa do Ministério da Saúde recém-publicada aponta que após os 56 anos apenas $37 \%$ das mulheres mantêm atividades sexuais. $\hat{E}$ um indice muito baixo, principalmente se comparado ao dos homens na mesma faixa etária, 93\%. A novidade é que agora elas não se conformam mais com esse papel e estão empenhadas em reverter o jogo [...]

Segundo os especialistas, ainda é grande o número de mulheres que decidem pôr fim à vida sexual precocemente. Muitas delas tiveram experiências ruins no passado e desistem de recomeçar.

\section{Revista Veja - p. 96}

20.10 .99

Na verdade, a grande parte das incorreções em coberturas de assuntos científicos e econômicos ocorre não por desonestidade, mas por falta de conhecimento de ambas as partes. No final de 1998, a Associação médica americana divulgou uma pesquisa feita durante dois anos e meio: foram divulgadas pela imprensa 235 pesquisas científicas que, como se descobriu posteriormente, continham erros. Mas, como a imprensa não acompanhou essas correções, as teses continuam sendo reproduzidas como se fossem verdadeiras. Este tipo de engano continua por causa do relacionamento 
conturbado entre jornalistas e pesquisadores. Mais de $70 \%$ dos cientistas, segundo levantamentos recentes, acham que a mídia está mais preocupada com sensacionalismo do que em noticiar dados mais substanciosos.

\section{COMO É “CONSTRUÍDA” A NOTÍCIA}

A escolha dos assuntos a serem abordados pela imprensa naquele dia é feita durante a reunião de pauta na qual comparece, normalmente, um pequeno grupo de jornalistas. Apenas eventualmente, quem redigirá as matérias participa da reunião. Da pauta constam um resumo do assunto, sugestões de nomes a serem entrevistados e a forma como o tema deverá ser abordado. A seleção das fontes de informação é o segundo momento em que essa subjetividade se faz presente.

"Extrair dessas fontes informações que as prejudiquem é, evidentemente, muito difícil, se não impossível. Cabe então, ao repórter, pesar cada informação passada pelas fontes, confrontá-la com outras, oriundas de outros informantes, avaliá-la em função de seus próprios conhecimentos ou informações anteriores sobre o tema - e, assim, compor o seu próprio quadro"?.

A não apuração dos fatos e das informações que chegam até as redações dos jornais vai levar, muitas vezes, à notícias que refletem apenas o interesse da indústria farmacêutica, divulgam pesquisas que ainda não foram aprovadas pela comunidade científica.

Apurados os fatos, colhidas e analisadas as informações, a notícia é, finalmente redigida. "Como escreve um jornalista?", pergunta o Manual de redação do Globo. A resposta vem em uma só palavra: rápido. Ainda segundo o manual, enquanto alguns textos exigem precisão de informação como os relatórios técnicos - ou elegância de estilo - como as obras literárias - o jornalismo exige tudo isso em um tempo determinado pela pressão do rígido horário para o fechamento do jornal. Entretanto, independente da velocidade em que se escreve, o estilo jornalístico pede textos claros, concisos, diretos, sintéticos e exatos. Dessa forma estará não apenas facilitando a leitura, mas também a compreensão das notícias.

A edição das páginas do jornal envolve a escolha das fotos, a redação das legendas, títulos e subtítulos e a distribuição espacial das matérias. Em algumas editorias, principalmente naquelas que noticiam fatos nacionais e internacionais, grande parte das matérias publicadas chegam aos jornais através das agências de notícias. Mais uma vez a subjetividade estará presente: o enfoque para a notícia será o enfoque escolhido pela agência que a produziu e a publicação ou não da matéria dependerá de uma seleção pessoal do editor.

Quem prepara os títulos ou faz cortes nas matérias, para atender exigências gráficas com relação ao tamanho das mesmas, não são os profissio- 
nais que as redigiram, mas o editor encarregado do fechamento da página. Isso poderá levar ao corte de alguma informação relevante ou a um título inadequado para o tema principal da notícia. As redações dos jornais estão divididas em editorias, mas a especialização ainda não é uma realidade da maioria dos profissionais.

A Folha de S. Paulo fez um teste de ética jornalística em abril de 97. Foram apresentadas cinco situações a 336 leitores e 12 editores do jornal. Para cada pergunta havia duas alternativas de respostas. À exceção de duas perguntas, leitores e editores optaram, majoritariamente, por decisões divergentes. Não houve unanimidade a favor de nenhuma alternativa, nem mesmo no restrito colégio de editores que responderam. Apenas numa questão houve coincidência entre editores e leitores, em sua maioria. Os dois grupos acham que vale a pena omitir informações quando elas não estão suficientemente checadas, apesar de serem fornecidas por autoridade policial. Vale considerar que entre leitores e editores houve quantidade considerável de respostas favoráveis à publicação ${ }^{8}$.

Por exemplo, leitores e editores discordaram sobre se o jornal deveria usar, na Primeira Página, fotografia da queda do presidente Fernando Henrique Cardoso ao subir no palanque. A maioria dos leitores respondeu que não. A maioria dos editores disse que sim.

\section{A IMPRENSA FEMININA}

O jornalismo ocupa um espaço quase acidental na imprensa feminina brasileira9. Se tivemos, no Brasil, desde meados do século passado, uma imprensa feminina, nem sempre tivemos um jornalismo feminino. "Qualquer pessoa relativamente esclarecida que eventualmente pare em frente a uma banca de jornal para espiar as opções que lhe oferecem pode ter a sensação incômoda de estar diante de um cemitério do feminismo - cada uma das revistas dedicadas à mulher sendo uma lápide dessa paisagem “, é o que afirma o crítico de TV Fernando de Barros Silva ${ }^{10}$.

As publicações periódicas destinadas à mulher quase nunca contemplam a atualidade (característica básica do jornalismo) e, portanto, configuram-se como produtos editoriais não-jornalísticos, apesar de corresponder aos padrões correntes da indústria cultural. Em geral trazem mais idéias do que fatos. Não há uma ancoragem temporal imediata. "Na medida em que o jornalismo tem sido historicamente uma atividade que enseja participação política, estimulando a intervenção crítica da realidade, é compreensível que as publicações femininas (conformistas, alienadoras) não abram espaço para o jornalismo. Fazê-lo seria talvez minar as suas próprias bases de sustentação" ". Ainda hoje, a imprensa feminina tem se esmerado em fazer crer à sua leitora que o mundo se reduz ao lar, às compras e à vida social. 


\section{CONCLUSÃO}

Qual a representação social da sexualidade humana construída a partir das notícias veiculadas pela imprensa e que tipo de informação está sendo passada para a sociedade? Nossa análise levou a algumas respostas. A imprensa acaba por construir uma realidade sobre a sexualidade humana que certamente influencia a atitude das pessoas frente ao tema. Por se tratar de um assunto em que as dúvidas e as incertezas científicas fazem parte da realidade, a grande imprensa, de uma maneira geral, não poderia deixar de refletir essas dúvidas e incertezas. Porém, a informação errada deve ser corrigida mas, antes de mais nada, deve ser evitada.

Outro aspecto diz respeito à desinformação de alguns jornalistas, que acreditamos, seja consequiência em parte, da falta de especialização. Eles escrevem sobre o que desconhecem e não têm tempo de conhecer.

Noticia-se sobre sexualidade praticamente todos os dias em editorias diversas tanto da imprensa impressa quanto da televisiva e radiofônica. O que se pretende com esse artigo é levantar questões que levem à reflexão sobre o papel e a responsabilidade, tanto dos profissionais da imprensa quanto dos especialistas no tema, na construção de uma sexualidade saudável e prazerosa.

Sobre jornais e aleluias Rubem Alves

"Não sei o que fazer com a maioria das notícias. Com a previsão do tempo é fácil. Ela diz que vai chover. Previno-me com o guarda-chuva. Mas a maioria das notícias não me permite qualquer ação prática. 'Serra declara que privatizar não resolve': manchete. A direção do jornal elegeu essa como a notícia mais importante do dia. Ó dia chato... Uma manchete, se eu fosse diretor de jornal teria de ser semelhante a um 'tema' que o jornal dá ao povo para que ele faça variações naquele dia: coisa para provocar a dança dos pensamentos. Aí eu me pergunto: 'Meu Deus, que variação posso eu, modesto cidadão, fazer com a informação de que o Serra disse que privatizar só não resolve?' Meu pensador fica parado".

Folha de São Paulo - 12.11.95

\section{REFERÊNCIAS BIBLIOGRÁFICAS}

1. MORAN, J. M. Interferências dos Meios de Comunicação no nosso Conhecimento. Intercon - Revista Brasileira de Comunicação, São Paulo, ano XVII, $\mathrm{n}^{\circ}$ 2, 1994. 
2. SOUZA, H. de. A TV no país das maravilhas. Revista Imprensa, São Paulo, ano V, mês 03, nº 55, mar./92.

3. PRETE, R. L. Meninos Perdidos. Folha de S. Paulo - 8 de nov. de $1998-$ p. 06 - Editoria Brasil.

4. NORA, P. Os acontecimentos e o historiador do presente. In: LE GOFF e outros. A Nova História. Lisboa, Edições 70, s/d.

5. LIPPMANN. W. Esteriótipos. In: STEINBERG, Ch (org.). Meios de Comunicação de Massa. São Paulo, Cultrix, 1970.

6. PRETE, R. L. Não basta ser bom. Folha de S. Paulo - 5 de set. 1999 - p. $06-$ Editoria Brasil.

7. ROSSI, C. O que é jornalismo. São Paulo, Brasiliense, 1995.

8. SANTOS, M. V. As respostas ao teste de ética. Folha de S. Paulo -25 de maio 1997.

9. MELO, J. M. de. Para uma leitura crítica da comunicação. Ed. Paulinas, São Paulo, 1985.

10. SILVA, F. B. Folha de S. Paulo - TV Folha, p. $02-24$ de out. 1999. 